\title{
Maintaining mood stability in bipolar disorder: a clinical perspective on pharmacotherapy
}

Gin S Malhi, ${ }^{1,2}$ Claire McAulay, ${ }^{1,2}$ Pritha Das, ${ }^{1,2}$ Kristina Fritz $^{1,2}$

${ }^{1}$ Discipline of Psychiatry, Sydney Medical School, University of Sydney, St Leonards, New South Wales, Australia; ${ }^{2}$ Department of Psychiatry, CADE Clinic, Royal North Shore Hospital, St Leonards, New South Wales, Australia

Correspondence to Professor Gin S Malhi; gin.malhi@sydney.edu.au

- Additional material is published online only. To view please visit the journal online (http://dx.doi.org/10.1136/eb-2014-101948).

\section{INTRODUCTION}

Bipolar disorder is defined by its poles, elevated mood or irritability characterises mania, and marked low mood and lack of energy typifies depression. Treatment of these acute states is necessary for the patient's well-being but the major management challenge lies in reducing the frequency and severity of relapses and recurrences, and maintaining healthy mood. Typically, patients with bipolar disorder experience a recurrence every 17-30 months and have multiple episodes over the course of the illness. ${ }^{1}$ Successful management of this chronic, recurrent illness ultimately depends on maintaining long-term mood stability and preventing further episodes of depression and mania. It is therefore, all the more remarkable that maintenance therapies have received sparse attention; this is partly because longitudinal research is difficult to design and conduct. Therefore, clinicians often have to draw on experience regarding the long-term use of medications. This paper outlines the options for long-term pharmacotherapy of bipolar disorder and addresses common clinical questions regarding administration, drawing on a synthesis of current evidence for maintenance agents.

\section{METHODS}

To identify relevant evidence for the long-term pharmacological management of bipolar disorder electronic database searches were conducted using Summon (the University of Sydney's cross-search engine), OvidSP (including PubMed and PsycINFO) and Cochrane reviews. Searches were limited to the past 7 years. In addition existing systematic reviews were carefully scrutinised and their bibliographies drawn on to identify additional studies of note which were appraised alongside recent clinical trials. This review primarily included studies that were randomised, placebo-controlled, blinded, non-enriched and of sufficient duration to be regarded as maintenance therapy. Studies that did not meet all these principal requirements, such as those with external validity in non-randomised settings, were also reviewed cautiously and their findings were considered with limitations. Their impact in determining treatment decisions was moderated accordingly. The need to institute this process reflects the paucity of robust evidence.

\section{Long-term treatment}

The key goal of long-term treatment is the prevention of future mood episodes, but in practice $100 \%$ prevention is exceptional. ${ }^{2}$ Almost half of all treated patients experience a recurrence within 2 years and $70-90 \%$ within 5 years. ${ }^{3}$ Therefore, the aims of long-term treatment have to be broader and include a reduction in inter-episode symptoms along with a reduction in the frequency and severity of episodes. ${ }^{2}$ Long-term treatment of bipolar disorder consists of a continuation stage and subsequent maintenance stage, as shown in figure 1.

The continuation stage of treatment begins immediately after the remission of acute symptoms. Generally, medication doses tend to be higher during the acute phase of the illness and thus, should be tapered down during continuation treatment. During this time, frequent follow-up and close supervision is necessary as patients remain vulnerable to relapse. Continuation treatment aims to sustain clinical improvement and prevent relapse and patient adherence is critical during this stage. ${ }^{4}$

Maintenance treatment starts once reasonable mood stability has been achieved following continuation treatment, which usually comprises 3-6 months of continued mood stability. Figure 1 shows successive progression through these treatment stages.

The long-term goal of maintenance treatment is to reach optimum (or premorbid) functioning, which includes maintaining optimal mood stability (see box 1) and the prevention of new mood episodes (recurrence).

\section{In practice: initiation}

Following diagnosis, a key issue in early management is the patient's acceptance of the chronic nature of bipolar disorder and the need for regular lifelong follow-up. Many patients first experience mania as adolescents or young adults ${ }^{5}$ and are daunted by the diagnosis, but frequent recurrences make the necessity of continual management evident.

The polarity of bipolar disorder usefully informs long-term pharmacotherapy, and while depression is more common (because depressive episodes tend to last longer), some patients are mania-dominant (especially early in the illness) or are equally likely to experience both
Figure 1 Transition from acute illness through the continuation and maintenance treatment. Note, the acute phase of mania is typically weeks whereas acute depressive episodes may last months.

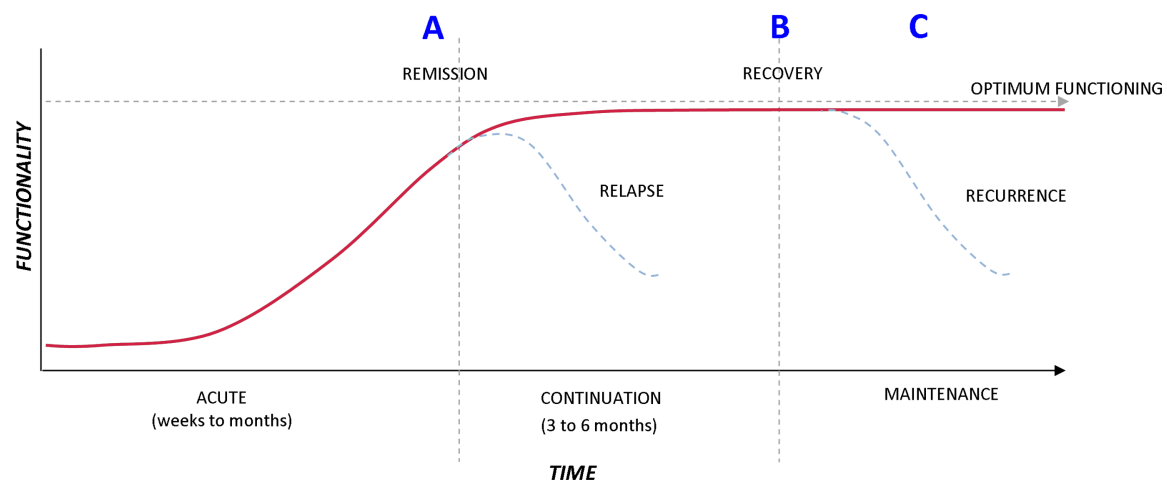




\section{Box 1 What is optimal mood stability?}

The definition of optimal mood stability is determined by a range of factors. Clinicians can rate the success of treatment strategies by assessing:

I. Number of relapses and recurrences

II. Residual subsyndromal symptoms

III. Occupational and social functioning

IV. Return to 'normalcy' as rated by the patient In addition, vitality and enjoyment of life are important considerations. For patients, the absence of acute mania and depression alone, while germane, does not necessarily constitute a return to health. Gaps in recovery, such as lingering problems with sleep, appetite, social life, home life and concentration, govern whether patients are able to readjust to 'normal' functioning, maintain medication adherence and make healthy lifestyle choices to promote wellness. Therefore, the efficacy of pharmacotherapies needs to be gauged against both quantitative and qualitative outcomes.

phases. This is important because some agents have greater efficacy for preventing mania or depression. ${ }^{6}$ Knowledge of the patient's illness pattern informs long-term goals, as debilitating depression may be a core treatment goal for some, whereas manic symptoms or lack of mood stability may cause greater functional impairment for others. ${ }^{6}$ Note, the pattern of polarity often changes over time and therefore the most recent episode is an important factor in treatment decisions. Primary and secondary continuation treatment options are illustrated in figure $2 A^{3}{ }^{7}$ Drugs that have shown past efficacy should be engaged before novel agents.

\section{Monitoring and adherence}

Following approximately 3-6 months of continuation treatment, patients enter the maintenance stage, where most or all symptoms have resolved and the focus is the prevention and promotion of healthy mood. Medications should be reassessed and any symptoms or sideeffects monitored regularly; this may inform the decision to either taper, increase or switch agents; further, manage associated health concerns, such as metabolic changes (see figure 2B).

In bipolar disorder, adherence to long-term treatment with medications is not achieved easily. Dissatisfaction with the efficacy of treatment, coupled with the additional burden of side effects, financial cost of regular follow-up and the desire to put the illness and its associated memories out of mind, all contribute to poor compliance and the likelihood of cessation. Indeed, almost all patients with bipolar disorder will have a period of poor compliance at some point in the course of their illness, but it is best to try and decrease these periods of non-adherence. The medication regimen may need to be modified in instances where reduced adherence is caused by poor tolerability, or where severe side effects, such as renal failure or metabolic syndrome, pose serious health risks. It is important to identify subsyndromal symptoms, as these can significantly limit functioning, and regularly review the effectiveness of ongoing treatment, so as to anticipate prodromal symptoms and future recurrences. ${ }^{8}$ Strategies of switching or stopping maintenance medication in order to address poor effectiveness or tolerance are outlined in figure $2 \mathrm{~B}$.

\section{Pharmacotherapy treatments}

Maintenance treatment research is relatively nascent, ${ }^{3}$ and therefore, there is a dearth of knowledge in comparison to the acute treatment of bipolar disorder. Furthermore, studies that have explored long-term treatment have many shortcomings. For example, they do not have sufficient long-term follow-up, they often fail to differentiate between remission versus relapse, and/or they do not clearly define and separate continuation and maintenance treatment. ${ }^{9} 10$ They often use 'enriched' patient samples (ie, assessing agents with known efficacy in specific patients), ${ }^{10}$ limiting generalisability of the findings. ${ }^{11}$ Furthermore, patients are usually admitted into studies while recovering from manic and mixed episodes, rather than depression, even though depression is the predominant phase of the illness $s^{11-13}$ and may confer greater functional impairment in the long term. ${ }^{5}$ These limitations inherently favour fast-acting agents such as second-generation antipsychotics, which primarily reduce agitation and assist sleep rather than stabilise mood and therefore, only offer benefit during the continuation stage. Thus, many second-generation antipsychotics (SGAs) are recommended as maintenance agents in treatment guidelines, which is problematic given the significant risks of metabolic and medical complications long term. ${ }^{10} 11$ Recent reviews have provided a small basis for specific maintenance agents. ${ }^{32-14}$ However, in addition to research design flaws, it must be noted that many agents have simply insufficient evidence and await the outcomes of further research. Until more suitable long-term studies are conducted, clinicians must exercise their best judgement and employ trial and error to determine the best long-term agents for individual patients, taking care to consider their polarity index. This served to offer due consideration to promising new research on maintenance. Figure 3 summarises the utility of some common maintenance agents.

\section{Mood stabilisers}

Lithium, the original mood stabiliser, remains the gold standard in bipolar management (for acute and long term), especially for manicdominant patients, and because of its prophylactic and antisuicidal properties. ${ }^{15}$ Approximately one-third of lithium-treated patients experience no further major episodes for up to 10 years, ${ }^{16}$ but this is not an excuse for complacency because abrupt cessation is quite likely to prompt recurrence. ${ }^{17}$ Monotherapy is ideal but often not adequate, and lithium can often be successfully combined with adjunctive lamotrigine or quetiapine.

\section{Anticonvulsants}

While valproate has reported empirical efficacy, only a few clinical trials support its long-term use. Interestingly, a recent review suggested that valproate may have superior tolerability compared to lithium for some patients. ${ }^{11}$ However, the BALANCE study, which had utilised a 2-year follow-up period, found that lithium was superior to valproate and that the combination of the two medications was better than either alone in preventing depressive recurrences. ${ }^{18}$

Lamotrigine is most effective as a bipolar maintenance agent with patients who experience depressive-dominant bipolar disorder. It has shown efficacy as monotherapy and as an adjunct to lithium in reducing the risk of recurrence, particularly of depression. ${ }^{4}{ }^{19-21}$ Carbamazepine is another option that has shown some efficacy predominantly as an adjunct, ${ }^{22}$ but due to its side effect burden, should be considered only after more readily-tolerated agents fail to yield benefits. ${ }^{3}$

\section{Second Generation Antipsychotics}

Newer Second Generation Antipsychotics (SGAs) are increasingly being proposed as viable long-term treatments for bipolar disorder, but substantive research only exists for two agents thus far-quetiapine and olanzapine. Quetiapine is a front-line monotherapeutic option and may suit patients with mixed features, rapid cycling, marked agitation and sleep deficits. ${ }^{12}$ It has been shown to be equivalent to lithium in prevention of recurrences and demonstrates efficacy in either polarity, but only in short-term studies that lack an active 

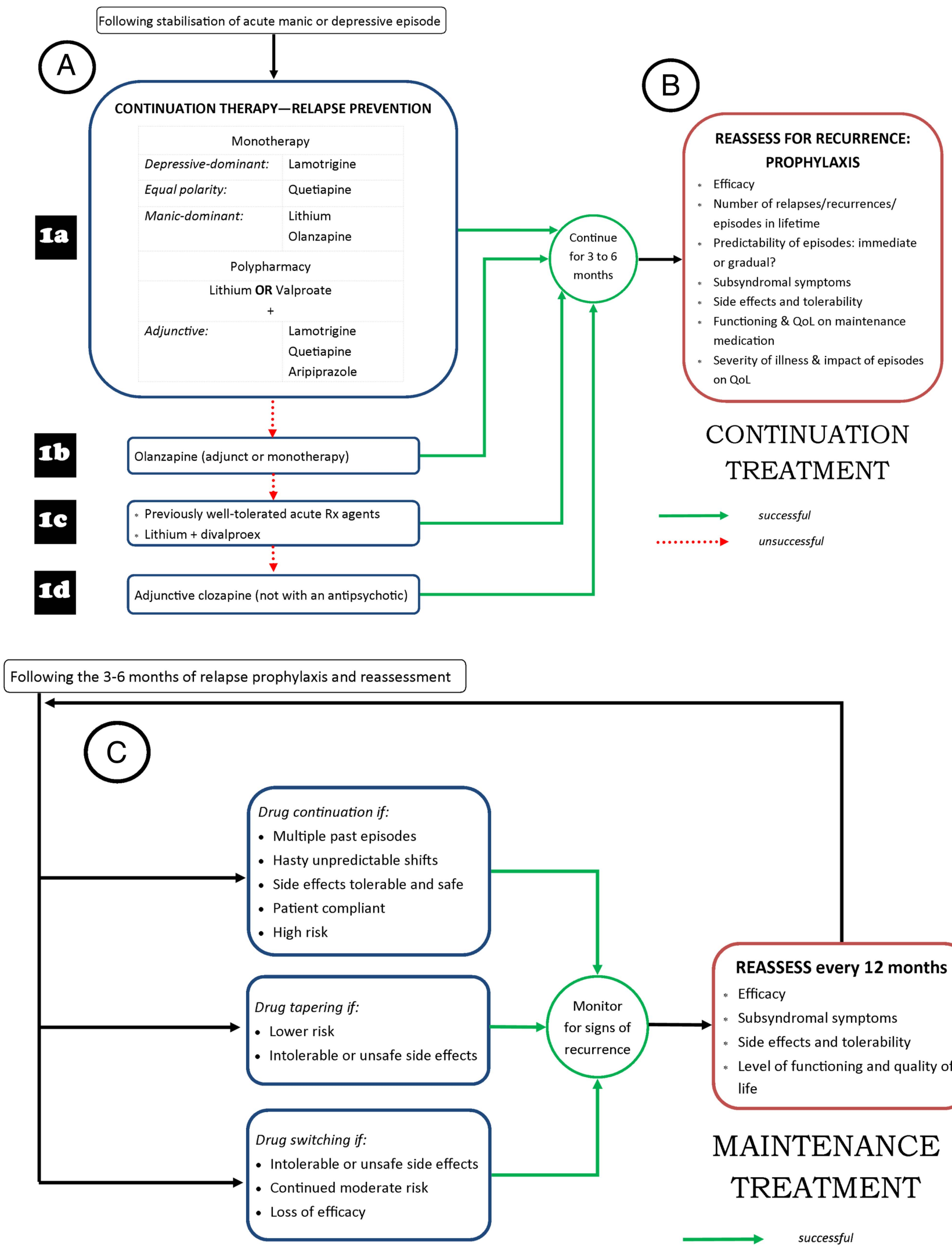

Figure 2 (A) Decision-making diagram for continuation treatment in bipolar disorder (QoL, quality of life). (B) Decision-making diagram for maintenance treatment in bipolar disorder.

comparator. ${ }^{23}$ Olanzapine is also commonly used as monotherapy, typically in manic-dominant patients. It is arguably comparable to valproate for preventing mania ${ }^{24}$ but has not shown efficacy in preventing depression. ${ }^{1325}$ Agents that show promise are being investigated; for example, the ARIQUELI study, currently nearing completion, examines whether aripiprazole (an SGA) confers benefit in preventing bipolar 


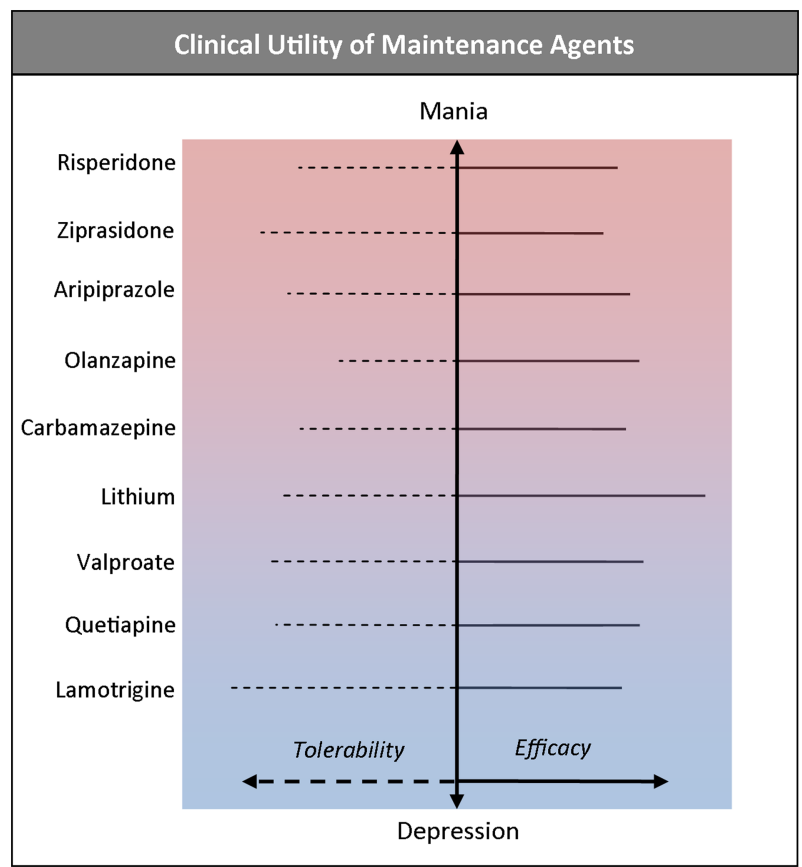

Figure 3 Efficacy and tolerability of maintenance agents.

disorder relapse and recurrence when administered as an adjunct to quetiapine or lithium. ${ }^{26}$ It has previously been shown some prophylactic efficacy against mania but not depression ${ }^{27}$ and as adjunct to lithium or valproate. ${ }^{28}$ Risperidone, a long-acting injectable, has been shown to improve outcomes and reduce the risk of manic recurrence. $^{3}{ }^{12}$ Clozapine is rarely recommended given its high risk of side effects but may suit treatment-resistant patients who are able to engage with regular monitoring. ${ }^{3}$

\section{Antidepressants}

Antidepressants are no longer recommended as monotherapy, partly due to questionable efficacy ${ }^{29}$ and the elevated risk of switching to mania with these agents. ${ }^{30}$ However, in treatment-resistant, depressivedominant patients, a selective serotonin reuptake inhibitor in combination with a mood stabiliser such as lithium may be suitable after exhausting alternative combinations; this requires a strict consideration of inherent risks. ${ }^{29}$ Table 1 summarises principal maintenance agents.

\section{Side effects}

Side effects of bipolar disorder agents are common during acute and continuation treatment, but can be alleviated to some extent by tapering in the maintenance stage. However, some distressing symptoms often persist. Some of the side effects are serious and only become apparent long-term. Therefore, clinicians must be cognisant of these tolerability issues and also need to be aware of the needs of different patient groups. For instance, women of childbearing age are susceptible to teratogenic side effects and treatment needs to be reviewed when planning pregnancy, while older patients may be at greater risk for acute or chronic toxicity and renal dysfunction. ${ }^{42}$

Naturally, different medications require separate schedules for monitoring side-effects or toxicity, and given that polypharmacy is common, patients may require quite frequent investigations and follow-up. Table 2 summarises recommended schedules for review.

\section{Patient diversity: disease and individual factors relevant to pharmacotherapy}

Few patients with bipolar disorder experience only a single episode of the illness during their lifetime and therefore, maintenance treatment is

Table 1 Optimal maintenance agents in bipolar disorder

\begin{tabular}{|c|c|c|c|}
\hline $\begin{array}{l}\text { Maintenance } \\
\text { agent }\end{array}$ & CBR* $^{*}$ & EBRt & Utility \\
\hline \multicolumn{4}{|l|}{ Mood stabiliser } \\
\hline Lithium & $\checkmark \checkmark \checkmark$ & Level I & $\begin{array}{l}\text { Classic frontline option for bipolar, especially mania-dominant. }{ }^{312}{ }^{31} \text { Commonly used as adjunct with atypical antipsychotics. } \\
\text { Requires close monitoring to maintain within therapeutic preventative levels. High risk of recurrence on abrupt cessation }{ }^{15}\end{array}$ \\
\hline \multicolumn{4}{|l|}{ Anticonvulsants } \\
\hline Carbamazepine & $\checkmark \checkmark$ & - & $\begin{array}{l}\text { Less effective than lithium; may confer greater benefit in combination with lithium than either alone.[32] May also suit } \\
\text { rapid-cyclers.[3] Not a first--line choice. High potential side-effect burden }{ }^{3}\end{array}$ \\
\hline Lamotrigine & $\checkmark \checkmark$ & Level III & $\begin{array}{l}\text { More effective for preventing depressive recurrence. }{ }^{12} \text { Commonly used in combination with an antimanic prophylactic agent but } \\
\text { may be suitable as monotherapy for depressive-dominant patients. }{ }^{33} \text { May be appropriate for non-classic cases with mixed } \\
\text { features or rapid cycling }{ }^{3}\end{array}$ \\
\hline Valproate & $\checkmark \checkmark$ & Level III & $\begin{array}{l}\text { Evidence not yet robust }{ }^{34} \text { but commonly used for maintenance. }{ }^{3} \text { Recent review found some limited evidence of maintenance } \\
\text { efficacy, as adjunct. }{ }^{14} \text { Evidence suggests better adherence than for lithium. }{ }^{14} \text { Strongly contraindicated in pregnancy }{ }^{12}\end{array}$ \\
\hline \multicolumn{4}{|c|}{ Second-generation antipsychotics } \\
\hline Aripiprazole & - & $\begin{array}{l}\text { Level III as } \\
\text { adjunct }\end{array}$ & $\begin{array}{l}\text { Currently being longitudinally tested }{ }^{26} \text { with previous research only supporting short-term benefit as monotherapy versus other } \\
\text { agents. }^{35} \text { Reduces or prevents manic and mixed more so than depressive symptoms }{ }^{12} 28\end{array}$ \\
\hline Clozapine & $\checkmark$ & - & High side-effect risk. Best suited in treatment-resistant cases after other avenues exhausted \\
\hline Olanzapine & $\checkmark \checkmark$ & Level III & $\begin{array}{l}\text { Somewhat efficacious for preventing manic and mixed relapse with mixed evidence for efficacy in depression. }{ }^{25} \text { High metabolic } \\
\text { risk with long-term use. Few studies of sufficient duration to investigate long-term maintenance rather than continuation. Much } \\
\text { evidence draws from enriched samples }{ }^{12}\end{array}$ \\
\hline Quetiapine & $\checkmark \checkmark$ & Level III & $\begin{array}{l}\text { Efficacious for preventing manic and depressive relapse. }{ }^{23}{ }^{36} \text { Suitable for rapid cyclers in short term. }{ }^{37} \text { Evidence of long-term } \\
\text { maintenance efficacy as adjunct }{ }^{38}\end{array}$ \\
\hline Risperidone-LAI & $\checkmark$ & $\begin{array}{l}\text { Level III as } \\
\text { adjunct }\end{array}$ & $\begin{array}{l}\text { Some enriched design results show maintenance efficacy as adjunct. }{ }^{39} 40 \text { Suitable if poor adherence early in treatment history. } \\
\text { Only potentially suitable as monotherapy in mania-dominant patients }{ }^{3}\end{array}$ \\
\hline Ziprasidone & $\checkmark$ & $\begin{array}{l}\text { Level III as } \\
\text { adjunct }\end{array}$ & Some evidence suggesting suitable as adjunct for long-term mania prophylaxis ${ }^{41}$ \\
\hline
\end{tabular}

*Consensus-based research derived from working group preparing Royal Australian and New Zealand College of Psychiatrists Clinical Practice Guideline: Mood Disorders for ANZJP. (Malhi et al, 2014; under consideration from ANZJP). Checks indicate strength of available evidence for use-3 indicates strong, 2 moderate or 1 limited.

tEvidence-based research using NHMRC levels of evidence. I, systematic review of level II studies; II, randomised controlled trial; III, other study designs using controls; IV, case series with post-test or pretest/post-test outcomes. 
Table 2 Assessment frequency for reviewing health effects of bipolar medications

\begin{tabular}{|c|c|c|c|c|c|}
\hline \multirow[b]{2}{*}{ Medication } & \multirow[b]{2}{*}{ Investigations/examinations } & \multicolumn{4}{|c|}{$\begin{array}{l}\text { Suggested assessment } \\
\text { timetable during } \\
\text { treatment (months) }\end{array}$} \\
\hline & & Initiation & 6 & 12 & 24 \\
\hline Carbamazepine & $\begin{array}{l}\text { Full blood count } \\
\text { Endocrine }\end{array}$ & $\begin{array}{l}2 \\
d\end{array}$ & $\begin{array}{l}2 \\
d\end{array}$ & $\begin{array}{l}2 \\
d\end{array}$ & \\
\hline Lamotrigine & Full blood count & $\checkmark$ & $\checkmark$ & $\checkmark$ & $\checkmark$ \\
\hline Lithium & $\begin{array}{l}\text { Renal (urea, creatinine, electrolytes) } \\
\text { Endocrine (TSH, Serum } \mathrm{Ca}^{2+} \text { ) } \\
\text { Physical (waist circumference, BMI) } \\
\text { Serum lithium estimations }\end{array}$ & $\begin{array}{l}2 \\
\checkmark \\
\checkmark \\
d\end{array}$ & $\begin{array}{l}2 \\
2 \\
2 \\
2\end{array}$ & $\begin{array}{l}2 \\
2 \\
d \\
d \\
d\end{array}$ & $\begin{array}{l}2 \\
2 \\
2 \\
2\end{array}$ \\
\hline Olanzapine & $\begin{array}{l}\text { Physical } \\
\text { Fasting glucose and lipids }\end{array}$ & $\begin{array}{l}2 \\
d\end{array}$ & $\begin{array}{l}2 \\
d\end{array}$ & $\begin{array}{l}d \\
d\end{array}$ & \\
\hline Quetiapine & $\begin{array}{l}\text { Physical } \\
\text { Fasting glucose and lipids }\end{array}$ & $\begin{array}{l}2 \\
d\end{array}$ & $\begin{array}{l}2 \\
d\end{array}$ & $\begin{array}{l}2 \\
d\end{array}$ & \\
\hline Valproate & $\begin{array}{l}\text { Full blood count } \\
\text { Blood pressure } \\
\text { Endocrine } \\
\text { Fasting glucose and lipids }\end{array}$ & $\begin{array}{l}2 \\
\checkmark \\
\checkmark \\
\checkmark\end{array}$ & $\begin{array}{l}1 \\
1 \\
2\end{array}$ & $\begin{array}{l}2 \\
\checkmark \\
d \\
d \\
d\end{array}$ & $\begin{array}{l}2 \\
2 \\
2 \\
2\end{array}$ \\
\hline
\end{tabular}

TSH, thyroid-stimulating hormone; BMI, body mass index.

Derived from Royal Australian and New Zealand College of Psychiatrists Clinical Practice Guideline: Mood Disorders. (Malhi et al, 2014; under consideration from ANZJP).

inevitable for most. From a management perspective, the need for pharmacotherapy is indisputable but patient preference is important and the nature and trajectory of the illness also play a significant role. 'Classic' bipolar I disorder is typically less treatment-resistant, partly because it does not usually encompass challenging features such as rapid cycling or mixed states. In contrast, bipolar II disorder may involve a complex pattern of illness, often including 'milder' or less acutely disruptive features that nonetheless can exert a significant functional burden. Similarly, the management of subsyndromal symptoms is probably more important than previously thought ${ }^{543}$ and medications may be appropriate alongside psychological therapy. ${ }^{44}$ Complex presentations of bipolar disorder are increasingly recognised and involve symptoms such as mixed states, agitation and mood lability, which perhaps respond better to carbamazepine ${ }^{3}$ or fast-acting antipsychotic agents given the significance of early response. ${ }^{7}$

If adherence becomes an issue then long-acting injectable agents reduce treatment burden and the risk of relapse. For a small number of patients, psychological approaches may serve as sufficient for prophylaxis and monitoring between more acute phases, especially after weighing up the potential benefits versus costs of medication. While not ideal, this may be preferable to irreparably damaging the therapeutic alliance by disregarding patient preferences. Box 2 seeks to address some common clinical questions about maintenance treatment.

\section{Adjunctive psychotherapy and novel adjunctive agents}

Bipolar disorder benefits from a multifaceted approach that targets lifestyle factors and psychological strategies to promote long-term wellbeing. This may include structured psychological therapy, such as interpersonal rhythm therapy, family-focussed therapy, cognitive-behavioural therapy or acceptance and commitment therapy. ${ }^{45}$ These have been shown to sustain health and prevent relapse, in conjunction with pharmacotherapy. ${ }^{7}$ Substance abuse is highly prevalent in this population and should be recognised as a potential trigger, alongside signs of a shift in mood and/or coping. ${ }^{46}$ Psychoeducation is therefore important for managing medication and promoting adherence, also managing the disease long term. ${ }^{45}$ Regular 12-month follow-up appointments with the clinician can serve to provide interepisode support as well as

\section{Box 2 Common clinical questions}

Common clinical questions about maintenance treatment Q: Do all patients need continuation and maintenance treatment? A: Continuation treatment is essential and maintenance treatment should last at least until the patient is fully functional. This usually requires maintenance treatment for at least 1224 months. Long term prophylaxis is often beneficial but may not be necessary in all cases, particularly if episodes are very infrequent. However, in practice, acceptance is a key barrier, especially immediately after diagnosis, which typically follows the initial manic or hypomanic episode.

Q: Is mood stability achievable with monotherapy?

A: Yes, but this only occurs in a minority of patients.

Combination treatment is usually necessary to achieve prophylaxis against both manic and depressive symptoms, as many agents have a predominant effect on one pole of the illness.

Q: Will another episode occur if patients adhere to maintenance treatment?

A: Yes, because the illness is recurrent by nature, and bipolar medications are not curative. All medications offer only symptomatic relief and at best reduce the likelihood of future episodes.

Q: How frequently should a patient on maintenance treatment be monitored?

A: Monitoring should be regular and as frequent as possible. Soon after an episode of illness 3-6 monthly follow-up is useful. Longer term six monthly and annual follow-up may be acceptable depending on the nature of the illness and the treatments being administered. When monitoring it is important to check for subsyndromal symptoms that may predict a more serious episode. This may be more often if medications are being switched or titrated. It is important to exercise clinical judgement (see figure 2B). Keeping a mood diary and engaging family and friends to monitor any symptoms can also be beneficial to help patients better manage their illness.

0 : Are 'drug holidays' an appropriate option?

A: This should be considered exceptionally or for reasons such as planned pregnancy, given the risk that medications will lose their prior efficacy on reinitiation and stopping medications runs the risk of relapse/recurrence. Psychoeducation can assist patient's comprehension about the prophylactic benefits of medications and the importance of compliance even when well.

screening for any noteworthy symptoms or disruption to functioning, from the disease or medication regime. ${ }^{44}$

In addition to healthy lifestyle, there are recent novel directions in adjunctive agents for bipolar disorder. For example, $N$-acetyl cysteine, a mitochondrial agent, has been shown to improve depressive symptoms by alleviating oxidative stress in the brain. ${ }^{47}$ This may improve long-term cognitive, psychosocial and functional impairment. $\Omega-3$ Fatty acids may also help with the cognitive burden of bipolar. ${ }^{7}$

\section{CONCLUSION}

Maintenance treatment and long-term prophylaxis are necessarily complicated and require sophisticated management. Pharmacotherapy is one component of a broader set of strategies. To be successful it requires an indepth understanding of the illness, the unique requirements of the patient and a robust therapeutic alliance. Long-term mood stability can be achieved but goals need to be realistic and 
management needs to include monitoring and modifications of medication in order for these to be fulfilled.

Competing interests None.

doi:10.1136/eb-2014-101948

\section{REFERENCES}

1. Angst J, Sellaro R. Historical perspectives and natural history of bipolar disorder. Biol Psychiatry 2000;48:445-57.

2. Miklowitz DJ, Gitlin MJ. Clinician's Guide to Bipolar Disorder: Integrating Pharmacology and Psychotherapy. New York: Guildford Publications, 2014:113-44.

3. Gitlin M, Frye MA. Maintenance therapies in bipolar disorders. Bipolar Disord 2012;14(Suppl 2):51-65.

4. Malhi GS, Bargh DM, Mclntyre R, et al. Balanced efficacy, safety, and tolerability recommendations for the clinical management of bipolar disorder. Bipolar Disord 2012;14(Suppl 2):1-21.

5. Goldberg JF, Harrow M. A 15-year prospective follow-up of bipolar affective disorders: comparisons with unipolar nonpsychotic depression. Bipolar Disord 2011;13:155-63.

6. Popovic D, Reinares M, Goikolea JM, et al. Polarity index of pharmacological agents used for maintenance treatment of bipolar disorder. Eur Neuropsychopharmacol 2012;22:339-46.

7. Malhi GS, Adams D, Lampe L, et al. Clinical practice recommendations for bipolar disorder. Acta Psychiatr Scand Suppl 2009;119:27-46.

8. Perlis RH, Ostacher MJ, Patel JK, et al. Predictors of recurrence in bipolar disorder: primary outcomes from the Systematic Treatment Enhancement Program for Bipolar Disorder (STEP-BD). Am J Psychiatry 2006;163:217-24.

9. Degenhardt EK, Gatz JL, Jacob J, et al. Predictors of relapse or recurrence in bipolar I disorder. J Affect Disord 2012;136:733-9

10. Goodwin FK, Whitham EA, Ghaemi SN. Maintenance treatment study designs in bipolar disorder: do they demonstrate that atypical neuroleptics (antipsychotics) are mood stabilizers? CNS Drugs 2011;25:819-27.

11. Cipriani A, Barbui C, Rendell J, et al. Clinical and regulatory implications of active run-in phases in long-term studies for bipolar disorder. Acta Psychiatr Scand 2014;129:328-42.

12. Vieta $\mathbf{E}$, Valentí M. Pharmacological management of bipolar depression: acute treatment, maintenance, and prophylaxis. CNS Drugs 2013;27:515-29.

13. Vieta $\mathbf{E}$, Günther 0 , Locklear J, et al. Effectiveness of psychotropic medications in the maintenance phase of bipolar disorder: a meta-analysis of randomized controlled trials. Int J Neuropsychopharmacol 2011;14:1029-49.

14. Cipriani A, Reid K, Young AH, et al. Valproic acid, valproate and divalproex in the maintenance treatment of bipolar disorder (review). Cochrane Database Syst Rev 2013;10:CD003196. http://onlinelibrary.wiley.com/doi/10.1002/14651858.CD003196/ pdf/standard (accessed 23 Jul 2014).

15. Malhi GS, Tanious M, Das P, et al. The science and practice of lithium therapy. Aust N Z J Psychiatry 2012;46:192-211.

16. Grof P. Excellent lithium responders: people whose lives have been changed by lithium prophylaxis. In: Birch N, Gallichio V, Becker R, eds. Lithium: 50 years of psychopharmacology. New perspectives in biomedical and clinical research. Cheshire, CT: Weidner Publishing Group, 1999:36-51.

17. Malhi GS, Tanious M, Das P, et al. Potential mechanisms of action of lithium in bipolar disorder. Current understanding. CNS Drugs 2013;27:135-53.

18. Geddes JR, Goodwin GM, Rendell J, et al. Lithium plus valproate combination therapy versus monotherapy for relapse prevention in bipolar I disorder (BALANCE): a randomised open-label trial. Lancet 2010;375:385-95

19. Goodwin GM, Bowden CL, Calabrese JR, et al. A pooled analysis of 2 placebo-controlled 18-month trials of lamotrigine and lithium maintenance in bipolar I disorder. J Clin Psychiatry 2004;65:432-41.

20. Licht RW, Nielsen JN, Gram LF, et al. Lamotrigine versus lithium as maintenance treatment in bipolar I disorder: an open, randomized effectiveness study mimicking clinical practice. The 6th trial of the Danish University Antidepressant Group (DUAG-6). Bipolar Disord 2010;12:483-93.

21. van der Loos ML, Mulder P, Hartong EG, et al. Long-term outcome of bipolar depressed patients receiving lamotrigine as add-on to lithium with the possibility of the addition of paroxetine in nonresponders: a randomized, placebo-controlled trial with a novel design. Bipolar Disord 2011;13:111-17.

22. Chen $\mathbf{C H}$, Lin SK. Carbamazepine treatment of bipolar disorder: a retrospective evaluation of naturalistic long-term outcomes. BMC Psychiatry 2012;12:47.
23. Weisler RH, Nolen WA, Neijber A, et al. Continuation of quetiapine versus switching to placebo or lithium for maintenance treatment of bipolar I disorder (Trial 144: a randomized controlled study). J Clin Psychiatry 2011:72:1452-64.

24. Tohen $\mathbf{M}$, Ketter TA, Zarate CA, et al. Olanzapine versus divalproex sodium for the treatment of acute mania and maintenance of remission: a 47-week study. Am J Psychiatry 2003;160:1263-71.

25. Cipriani A, Rendell JM, Geddes J. Olanzapine in long-term treatment for bipolar disorder (review). Cochrane Database Syst Rev 2009;(1):CD004367.

26. Missio G, Moreno DH, Fernandes F, et al. The ARIQUELI study: potentiation of quetiapine in bipolar I nonresponders with lithium versus aripiprazole. Trials 2013;14:190

27. Yatham LN. A clinical review of aripiprazole in bipolar depression and maintenance therapy of bipolar disorder. J Affect Disord 2011;128(Suppl):S21-8.

28. Yatham LN, Fountoulakis KN, Rahman Z, et al. Efficacy of aripiprazole versus placebo as adjuncts to lithium or valproate in relapse prevention of manic or mixed episodes in bipolar I patients stratified by index manic or mixed episode. J Affect Disord 2013;147:365-72.

29. Pacchiarotti I, Bond DJ, Baldessarini RJ, et al. The International Society for Bipolar Disorders (ISBD) task force report on antidepressant use in bipolar disorders. Am J Psychiatry 2013;170:1249-62.

30. Valentí M, Pacchiarotti I, Bonnín CM, et al. Risk factors for antidepressant-related switch to mania. J Clin Psychiatry 2012;73:e271-6.

31. Burgess S, Geddes J, Hawton K, et al. Lithium for maintenance treatment of mood disorders. Cochrane Database Syst Rev 2001;(3):CD003013.

32. Denicoff KD, Smith-Jackson EE, Disney ER, et al. Comparative prophylactic efficacy of lithium, carbamazepine, and the combination in bipolar disorder. J Clin Psychiatry 1997; 58:470-8.

33. Goldsmith DR, Wagstaff AJ, Ibbotson $T$, et al. Lamotrigine: a review of its use in bipolar disorder. Drugs 2003;63:2029-50.

34. Bowden CL, Calabrese JR, McElroy SL, et al. A randomized, placebo-controlled 12-month trial of divalproex and lithium in treatment of outpatients with bipolar disorder. Divalproex Maintenance Study Group. Arch Gen Psychiatry 2000;57:481-9

35. Zupancic $\mathbf{M}$, Gonzalez ML. Aripiprazole in the acute and maintenance phase of bipolar I disorder. Ther Clin Risk Manag 2012;8:1-6.

36. Weisler RH, Montgomery SA, Earley WR, et al. Efficacy of extended release quetiapine fumarate monotherapy in patients with major depressive disorder: a pooled analysis of two 6-week, double-blind, placebo-controlled studies. Int Clin Psychopharmacol 2012;27:27-39.

37. Vieta $\mathbf{E}$, Calabrese JR, Goikolea JM, et al. Quetiapine monotherapy in the treatment of patients with bipolar I or II depression and a rapid-cycling disease course: a randomized, double-blind, placebo-controlled study. Bipolar Disord 2007;9:413-25

38. Chiesa A, Chierzi F, De Ronchi D, et al. Quetiapine for bipolar depression: a systematic review and meta-analysis. Int Clin Psychopharmacol 2012;27:76-90.

39. Quiroz JA, Yatham LN, Palumbo JM, et al. Risperidone long-acting injectable monotherapy in the maintenance treatment of bipolar I disorder. Biol Psychiatry 2010;68:156-62.

40. Macfadden W, Alphs L, Haskins JT, et al. A randomized, double-blind placebo-controlled study of maintenance treatment with adjunctive risperidone long-acting therapy in patients with bipolar I disorder who relapse frequently. Bipolar Disord 2009;11:827-39.

41. Bowden CL, Vieta E, Ice KS, et al. Ziprasidone plus a mood stabilizer in subjects with bipolar I disorder: a 6-month, randomized, placebo-controlled, double-blind trial. J Clin Psychiatry 2010;71:130-7.

42. Malhi GS, Adams D, Berk M. Medicating mood with maintenance in mind: bipolar depression pharmacotherapy. Bipolar Disord 2009;11(Suppl 2):55-76.

43. Marangell LB, Dennehy EB, Miyahara $S$, et al. The functional impact of subsyndromal depressive symptoms in bipolar disorder: data from STEP-BD. J Affect Disord 2009;114:58-67.

44. Scott J, Colom F, Vieta E. A meta-analysis of relapse rates with adjunctive psychological therapies compared to usual psychiatric treatment for bipolar disorders. Int J Neuropsychopharmacol 2007;10:123-9.

45. Geddes JR, Miklowitz DJ. Treatment of bipolar disorder. Lancet 2013;381:1672-82.

46. Malhi GS, Bargh DM, Cashman E, et al. The clinical management of bipolar disorder complexity using a stratified model. Bipolar Disord 2012;14(Suppl 2):66-89.

47. Berk M, Copolov DL, Dean O, et al. N-acetyl cysteine for depressive symptoms in bipolar disorder-a double-blind randomized placebo-controlled trial. Biol Psychiatry 2008;64:468-75. 